\title{
Value-Based Decision Making: Decision Theory Meets e-Government
}

\author{
Leif Sundberg $^{(\varpi)}$ and Katarina L. Gidlund \\ Mid Sweden University, Holmgatan 10, 85170 Sundsvall, Sweden \\ \{leif.sundberg, katarina.1.gidlund\}@miun.se
}

\begin{abstract}
Electronic government, or e-Government, is the use of information and communication technology in the public sector. As a research field, it is characterized as multi-disciplinary with heritage from both the information systems and public administration fields. This diverse background may be beneficial, but it may also result in a fragmented theoretical base and conceptual vagueness. This paper applies decision theory to e-Government to tie a number of theoretical and practical concepts together. In particular, five concepts from decision theory (i.e. objectives, stakeholder inclusion, weighting and resource allocation, risk analysis, and outcomes assessment) are compared with counterparts in e-Government. The findings have both theoretical and practical implications. First, they add to and unite e-Government theory. Second, practical methods for operationalizing the theoretical concepts are proposed. This operationalization includes using a holistic approach to e-participation throughout decision processes.
\end{abstract}

Keywords: Public values $\cdot$ Decision theory $\cdot$ Decision making $\cdot$ e-Government

\section{Introduction}

Electronic government, or e-Government, is the use of information and communication technology (ICT) in the public sector to create better government [1]. As a research field, e-Government is studied by multiple disciplines utilizing a variety of theories and methods. Some scholars define the field as theoretically weak and assert that much of the research lacks practical implications. They also express concerns about conceptual and definitional vagueness [2,3]. However, others have a more optimistic view; for instance, Bannister and Connolly [4] argue that a great deal of valuable theory exists in the e-Government field.

e-Government is often mentioned in relation to a paradigm shift in which a full range of democratic and institutional values are relevant. To realize these values, government agencies are supposed to collaborate and include citizens in their processes. The citizen becomes a problem solver who is actively engaged in producing values [5]. Dunleavy et al. [6] use the term "digital era governance" to describe these changes in government. They identify three characteristic themes: reintegration (as opposed to fragmentation), needs-based holism (i.e. reorganization 
to create seamless, non-stop solutions) and digitization processes (electronic service delivery).

Nonetheless, the outcomes of the above-described change have many uncertainties and alternate possibilities. For instance, Budzier and Flyvbjerg [7] have examined highrisk e-Government projects, which they refer to as "black swans." As a counter-measure against black swans, they suggest establishing efficient decision making to enable the early detection of anomalies. Pardo and Burke [8] argue that unstructured and nontransparent decision processes hinder the realization of public values and citizen trust. A longitudinal field study of the private sector reveals that managers who apply a high degree of procedural rationality in strategic decision making generally take better decisions [9]; unfortunately, few such studies have been conducted in relation to the public sector. Andersson et al. [10] investigate the challenges of implementing decision support systems (DSS) in a political context and conclude that a number of issues affect the outcomes, including a lack of impact on final decisions: the attitude among some of the decision makers in the study was that the political decision process could not be reduced to science, which meant they did not consider the DSS results when taking their final decisions.

Against this backdrop, the purpose of this paper is to apply decision theory to eGovernment. The aim of doing so is to contribute to the theoretical base of the eGovernment field and to tie several research issues within this field together by merging them with concepts from decision theory. The results should also offer practical benefits, by inspiring public managers to adapt more holistic and structured decision making.

This paper proceeds as follow. The method used is described in Sect. 2. Section 3 then presents a literature study, which is the main part of this paper. The results are then summarized in Sect. 4, which also contains suggestions for further research.

\section{Method}

The underlying method used in this paper is concept analysis, as visualized in Fig. 1. Concept analysis can be described as clarifying and describing the characteristics and relations that concepts have within a system.

Concept analysis is applied as follows in the current study. The goal (1.1 in the figure) is stated in the above introduction and the domains (1.2 in the figure) are the research fields of decision theory and e-Government. The premise is that the domains have concepts (1.3 in the figure) that overlap or are close. Decision theory can be used to gather the fragmented concepts from e-Government into one system.

Concept analysis has been operationalized by identifying five concepts that represent a structured decision-making procedure, namely:

- Objectives

- Stakeholder inclusion

- Weighting and resource allocation

- Risk analysis

- Outcomes assessment 


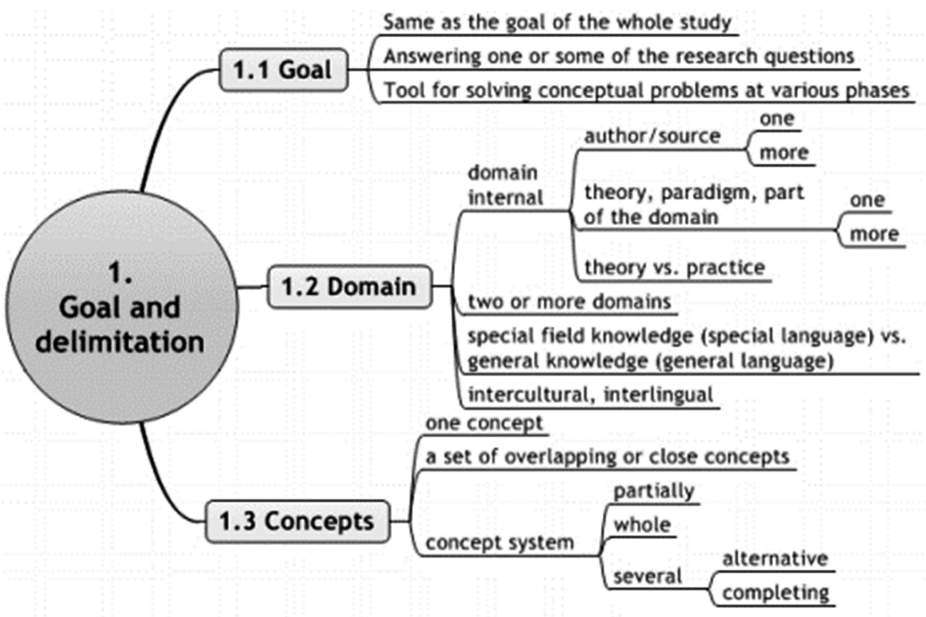

Fig. 1. Concept analysis [11]

These concepts are described using decision theory literature and then compared with their counterparts from the e-Government literature.

\section{Applying Decision Theory to e-Government}

This section starts with a general description of decision theory, which is followed by an introduction to the concepts explored in the study (namely objectives, stakeholder inclusion, weighting and resource allocation, risk analysis, and outcomes assessment). In addition, each concept is matched to an e-Government counterpart. Where applicable, a practical method for operationalizing it is also suggested.

\subsection{Overview of Decision Theory}

Humans make a number of decisions every day. The science of decision theory aims to understand the reasoning behind an agent's choices as well as to improve decision making. Descriptive decision theory is concerned with how people actually make decisions, whereas prescriptive decision theory is devoted to providing assistance that improves decision making [12]. The underlying goal of the decision analysis field is to contribute to rational decision making, and thus to increase the likelihood of fulfilling the decision maker's objectives and acting in accordance with his or her desires and values. However, no clear definition of rationality exists and a successful decision might not always be based on rational grounds.

In situations with high uncertainty, it might be nearly impossible for a decision maker to know which path to choose [13]. To reduce uncertainty in decision making and thereby improve outcomes, decision theory provides several structured proceedings to aid decision makers. However, decision problems are often complex and not ideally framed and 
humans are driven by a broad spectrum of values; as such, what is rational is also contested (see e.g. [14]).

\subsection{Objectives}

Every decision-making situation is dependent on a set of context-specific objectives [13]. According to Keeney [15], values are fundamental to everything we do and should be the primary driving force for decision making. By adopting a decision-making method known as value-focused thinking (VFT), better alternatives and decision situations can be generated by focusing on values: Some values are more important than others in a particular context, and they should serve as the foundation for all decision making. Values and objectives can conflict, but they can also be constructed in hierarchies of means and ends. According to VFT, end values can be identified by asking "Why is this objective important?" If the objective is important because if promotes another objective, it is a means objective; if it is important for its own sake, it is an end objective that should guide all decisions. In the public sector, a specific classification range of public values is frequently mentioned [16]. Bannister and Connolly [17] define public values as a mode of behavior that is held to be right. According to Bozeman [18], public values can be described as a normative consensus about rights, obligations and principles between citizens and the government. Values in e-Government can be classified in different ways depending on their properties in relation both to each other and to governmental paradigms $[19,20]$.

\subsection{Stakeholder Inclusion}

Values are subjective by nature, which means they can be ascribed to individuals or groups. To incorporate public value thinking into decision-making practices, public managers need to rigorously identify stakeholders [21]. Involving important stakeholders throughout a decision process enables both a better decision-making situation and the construction of additional alternatives [15]. Zhu and Kindarto [22] observe that participative decision structures are associated with IT project success in developing countries while more hierarchical structures hurt performance. The link between stakeholders and success is especially important in the public sector, since a system's user group may be both extensive and varying. A large stream in the e-Government literature is devoted to issues concerning e-participation and citizen empowerment. While participative governance is often treated as a success factor, concerns about how to extract a representative number of values from a limited pool of stakeholders also exist [23].

\subsection{Weighting and Resource Allocation}

Strategic decision making includes allocating limited resources in a way that achieves objectives [24, 25]. Fiscal funds are a democratic government's basic resource. As Moore [16] points out, public managers cannot produce desirable results without utilizing limited resources that have value for multiple uses. When conflicting objectives exist, they must be properly weighted as part of resource allocation and activity planning. 
Tools such as multi-criteria decision analysis (MCDA) can be used to quantify independent criteria in order to associate them with different weights. Riabacke et al. [26] suggest utilizing MCDA to improve decision quality in large-scale participatory processes.

In the e-Government context, the difficulty becomes prioritizing a broad range of public values; some services might target most of a country's population. As Bannister and Connolly [17] point out, implementing ICT:s is not value free but requires decisions about - and sometimes trade-offs between - values. Rose et al. [19] describe how public managers in a case study tended to prioritize administrative efficiency values while neglecting citizen engagement values. The findings of these studies illustrate that rationality is thus both contested and context-dependent. However, some researchers are attempting to identifying ways to make value prioritization more inclusive; for instance Robbins et al. [27] introduce resource allocation to eParticipation by using a web-based survey tool that enables respondents to take the fiscal impacts of their choices into consideration.

\subsection{Risk Analysis}

The definition of risk varies to some extent [28], with the common denominators being (a) uncertainty concerning future events and (b) the potential loss of something of value to humans. Epistemologically, risk is often divided into two categories: objective and subjective. Objective risk is based on statistics and earlier experiences, from which the probability that events will occur in the future can be extracted. Aven and Renn [29] argue that uncertainties are not objective parts of the world, but rather human constructs that an individual needs to assess. Subjective risk is dependent on personal beliefs. In the heart of subjectivist theory lies Bayes' theorem, which tells us that we can largely create any probability statement based on current information. New information makes it possible to revise earlier statements. Bayesian risk analysis has been adapted to eGovernment in a handful of cases [30, 31].

The word "risk" came to the English language in the 1660s through a French adoption of the Italian word "riscare," which means to navigate among dangerous rocks (as mentioned by Rosa [32]). An early paper on risk in relation to e-Government (with the suitable title of "Walking atop the cliffs") states that the causes of failures in this context are intertwined with technical, social and behavioral factors [33]. Røberg et al. [34] mention that research on risk and risk management in relation to e-Government is sparse. However, "challenges," "barriers" and similar terms are used as opposites to success factors in both information systems and e-Government literature. Sundberg [35] suggests defining risk in e-Government as potential threats to public values.

\subsection{Outcomes Assessment}

The final concept is a highly debated topic in the information systems literature: How do we assess the outcomes of implementing technology in a specific context? The main challenge is putting hard numbers on soft values. Traditional assessment methods such as cost-benefit analysis might fail to reflect the true costs and benefits of e-Government 
[36]. As such, frameworks that consider dimensions beyond monetary/efficiency values are needed [37, 38]. Scott et al. [39] suggest applying public value theory in order to evaluate e-Government success. Their approach consists of considering three categories of net benefits that comprise several public values, namely efficiency (cost, time, communication), effectiveness (avoid personal interaction, control, convenience, personalization, ease of information retrieval) and improved democracy (trust, wellinformedness and participation in decision making).

\section{Conclusions and Future Research}

This paper has compared five concepts of decision theory to their theoretical counterparts in e-Government. The results reveal that a number of theoretical concepts of e-Government fit well within decision theory, as shown in Table 1 where each concept is also accompanied by an example of a practical method.

Table 1. Concept system: Decision theory meets e-Government

\begin{tabular}{|c|c|c|c|c|}
\hline & $\begin{array}{l}\text { Decision theory } \\
\text { concept }\end{array}$ & $\begin{array}{l}\text { e-Government } \\
\text { concept }\end{array}$ & $\begin{array}{l}\text { Examples of } \\
\text { methods }\end{array}$ & \\
\hline \multirow[t]{4}{*}{$\begin{array}{l}\text { Stakeholder } \\
\text { inclusion }\end{array}$} & Objectives & Public values & $\begin{array}{l}\text { Value-focused } \\
\text { thinking }\end{array}$ & \multirow[t]{4}{*}{ eParticipation } \\
\hline & $\begin{array}{l}\text { Weighting and } \\
\text { resource allocation }\end{array}$ & $\begin{array}{l}\text { Prioritizing } \\
\text { between values and } \\
\text { allocating public } \\
\text { funds }\end{array}$ & $\begin{array}{l}\text { Multi-criteria } \\
\text { decision analysis; } \\
\text { web-based surveys } \\
\text { (with fiscal } \\
\text { implications) }\end{array}$ & \\
\hline & Risk & $\begin{array}{l}\text { Barriers and } \\
\text { challenges that } \\
\text { prevent value } \\
\text { realization }\end{array}$ & $\begin{array}{l}\text { Bayesian risk } \\
\text { analysis }\end{array}$ & \\
\hline & $\begin{array}{l}\text { Quantitative } \\
\text { outcomes } \\
\text { assessment }\end{array}$ & $\begin{array}{l}\text { Multi-dimensional } \\
\text { evaluation }\end{array}$ & $\begin{array}{l}\text { Public value net } \\
\text { benefits }\end{array}$ & \\
\hline
\end{tabular}

Stakeholder inclusion and eParticipation are placed on the sides of the table since they are frequently mentioned as success factors in the concepts, with the exception of risk analysis. Risk in e-Government still lacks clear conceptualization, even though implementing ICTs in the public sector is often seen as high-risk initiatives. This paper suggests using a risk analysis method that is based on subjective Bayesian probabilities which could enable future research to base risk assessment on participatory processes (through stakeholder-based probabilities).

The practical output of this paper is a holistic approach to (e-)participation in which different methods are used to include stakeholders throughout the decision process and participation is actually assessed as an outcome. The authors believe that this approach would benefit public managers by helping them to navigate an uncertain reality. Decision theory is not suggested as a universal solution to complex problems such as participative 
government and outcomes assessment; however, it does both improve structuring and help to fit these problems into a holistic theoretical and practical context. At the same time, decision theory could benefit from the e-Government field by addressing the challenges of a complex socio-technical field in which rationality is contested through paradigms, politics and organizational and stakeholder diversity.

This paper is based on a small sample of studies from two diverse research fields. Future research could add more to the topic by taking a more systematic approach to the literature, as well as by considering cases in which practical methods have been successfully applied.

\section{References}

1. OECD: The e-Government Imperative. OECD Publications, Paris (2003)

2. Heeks, R., Bailur, S.: Analyzing e-government research: perspectives, philosophies, theories, methods and practice. Gov. Inf. Q. 24, 243-265 (2007)

3. Yildiz, M.: e-Government research: reviewing the literature, limitations and ways forward. Gov. Inf. Q. 24, 646-665 (2007)

4. Bannister, F., Connolly, R.: The great theory hunt: does e-Government really have a problem? Gov. Inf. Q. 32, 1-11 (2014)

5. Bryson, J.M., Crosby, B.C., Bloomberg, L.: Public value governance: moving beyond traditional public administration and the new public management. Public Adm. Rev. 74, 445456 (2014)

6. Dunleavy, P., Margetts, H., Bastow, S., Tinkler, J.: New public management is dead-long live digital-era governance. J. Public Adm. Res. Theory 16, 467-494 (2005)

7. Budzier, A., Flyvbjerg, B.: Overspend? Late? Failure? What the data say about IT project risk in the public sector. In: Commonwealth Governance Handbook (2012/2013)

8. Pardo, T., Burke, B.: Government Worth Having: A Briefing on Interoperability for Government Leaders. Center for Technology in Government, University of Albany, Albany, NY (2008)

9. Dean Jr., W.D., Sharfman, M.P.: Does decision process matter? A study of strategic decisionmaking effectiveness. Acad. Manag. J. 39, 368-396 (1996)

10. Andersson, A., Grönlund, А., Åström, J.: You can’t make this a science! Analyzing decision support systems in political contexts. Gov. Inf. Q. 29, 543-552 (2012)

11. Nuopponen, A.: Methods of concept analysis-towards systematic concept analysis. LSP J. 1, 5-14 (2010)

12. Keeney, R.L.: On the foundations of prescriptive decision analysis. In: Edwards, W. (ed.) Utility Theories: Measurement and Applications. Kluwer Academic, Boston (1992)

13. Eisenführ, F., Weber, M., Langer, T.: Rational Decision Making. Springer, Heidenberg (2010)

14. Webler, T., Renn, O., Jaeger, C., Rosa, E.: The rational actor paradigm in risk theories: analysis and critique. In: Risk in the Modern Age: Social Theory, Science, and Environmental Decision Making, New York, pp. 35-61 (2001)

15. Keeney, R.L.: Value Focused Thinking: A Path to Creative Decisionmaking. Harvard University Press, Cambridge (1992)

16. Moore, M.H.: Creating Public Value: Strategic Management in Government. Harvard University Press, London (1995)

17. Bannister, F., Connolly, R.: ICT, public values and transformative government: a framework and programme for research. Gov. Inf. Q. 31, 119-128 (2014)

18. Bozeman, B.: Public values theory: three big questions. Int. J. Public Policy 4, 369-375 (2009) 
19. Rose, J., Persson, J.S., Heeager, L.T.: Competing value paradigms of e-Government managers: the efficiency imperative. Inform. Polity 20, 35-59 (2015)

20. Jørgensen, T.B., Bozeman, B.: Public values: an inventory. Admin. Soc. 39, 354-381 (2007)

21. Cook, M.E., Harrison, T.M.: Using public value thinking for government IT planning and decision making. In: Proceedings of the 15th Annual International Conference on Digital Government Research, pp. 54-60 (2014)

22. Zhu, Y.Q., Kindarto, A.: A garbage can model of government IT project failures in developing countries: the effects of leadership, decision structure and team competence. Gov. Inf. Q. 33, 629-637 (2016)

23. Gidlund, K.L.: Designing for all and no one-practitioners understandings of citizen driven development of public e-services. In: Proceedings of the 12th Participatory Design Conference 1, pp. 11-19 (2012)

24. Kleinmuntz, D.: Resource allocation decisions. In: Edwards, M., von Winterfeldt, D. (eds.) Advances in Decision Sciences. Cambridge University Press, Cambridge (2007)

25. Phillips, L.D., Bana e Costa, C.A.: Transparent prioritisation, budgeting and resource allocation with multi-criteria decision analysis and decision conferencing. Ann. Oper. Res. 154, 51-68 (2007)

26. Riabacke, M., Åström, J., Grönlund, Å.: Eparticipation galore? Extending multi-criteria decision analysis to the public. Int. J. Public Inf. Syst. 7, 79-99 (2011)

27. Robbins, M.D., Simonsen, B., Feldman, B.: Citizens and resource allocation: improving decision making with interactive web-based citizen participation. Public Adm. Rev. 68, 564575 (2008)

28. Hansson, S.O.: The epistemology of technological risk. Tecné 9, 68-80 (2007)

29. Aven, T., Renn, O.: On risk defined as an event where the outcome is uncertain. J. Risk Res. 12, 1-11 (2009)

30. Vrček, N., Peharda, P., Munđar, D.: Methodology for risk assessment and costs associated with risk occurrence in e-Government projects. In: Transportation Systems and Engineering: Concepts, Methodologies, Tools and Applications. IGI Global (2013)

31. Xia, A.: Research of e-Government security risk assessment method using bayesian network. In: International Conference on Web Information Systems and Mining (2009)

32. Rosa, E.A.: Metatheoretical foundations for post-normal risk. J. Risk Res. 1, 15-44 (1998)

33. Pardo, T.A., Scholl, H.J.: Walking atop the cliffs: avoiding failure and reducing risk in large scale e-Government projects. In: Proceedings of the 35th Annual Hawaii International Conference on System Sciences (2002)

34. Røberg, P.M., Flak, L.S., Myrseth, P.: Unveiling barriers and enablers of risk management in interoperability efforts. In: Proceedings of the 47th Hawaii International Conference on System Science (2014)

35. Sundberg, L.: Risk and decision in collaborative e-Government: an objectives-oriented approach. Electr. J. e-Gov. 14, 36-47 (2016)

36. Heeks, R.: Implementing and Managing e-Government: An International Text. Sage, London (2006)

37. Chircu, A.M.: e-Government evaluation: towards a multidimensional framework. Electr. Gov. Int. J. 5, 345-363 (2008)

38. Luna-Reyes, L.F., Gil-Garcia, J.R., Romero, G.: Towards a multidimensional model for evaluating electronic government: proposing a more comprehensive and integrative perspective. Gov. Inf. Q. 29, 324-334 (2012)

39. Scott, M., DeLone, W., Golden, W.: Measuring eGovernment success: a public value approach. Eur. J. Inf. Syst. 25, 187-208 (2016) 